\title{
Global Supply Chain Management: Challenges and Solution
}

\author{
Neerosha Rajah*, Haslinda Musa, Victor Nipis, Prasad Kunjee Krishnan, Sujitra Suppiah, Amir Fyrdaus Norull \\ Ahmad \\ Faculty of Technology Management and Technopreneurship, Universiti Teknikal Malaysia Melaka, Hang Tuah Jaya, 76100 Melaka, \\ Malaysia \\ *Corresponding authorE-mail: haslindamusa@utem.edu.my
}

\begin{abstract}
Efficient supply chain management is crucial for survival and success in a turbulent world. Current economic crisis increases its importance even further. This conceptual paper reviews latest findings in the most relevant areas of supply chain management. The objective of this paper is to identify global supply chain management challenges and its solutions. In order to achieve the objectives, a thorough literature review was conducted; main findings are reviewed. This review has covered Indian industry, HaiHa's supplier, and other global perspectives. Therefore, the challenges might be different according to the origin countries and industries. Besides, it is also found that the challenges can be mitigated with some alternatives derived from reviewing the case studies. The findings shown that in order to compete with global participation, efforts on seeking out the solutions would be much encouraged and embedded into the organizations.
\end{abstract}

Keywords: Global supply chain management; challenges, solutions; Indian industry; global perspectives.

\section{Introduction}

The economic growth in every country is depending much on its companies, as we can see they are growing locally as well as global business activities. Going global implies that supply chains are no more local [43]. This is proven when firms spread their operations across the globe sourcing from and selling to different organizations and or people. This fact adds complexity to the supply chain and if this complexity is not properly managed it can result in disruptions and higher costs [11].

Local business might be encountering some issues pertaining to the domestic rules and regulations, socials, economics and political areas [12]. Those issues more or less can be anticipated by the business institutions as they have experienced and familiarized it before, less constrained due to the issues are still under control. As compared to global business, where all factors beyond the boundaries, business operations might be restricted and less powerful players will suffer losses and closing their business operations. A good understanding on each country's policies should be addressed on so that the business can enter into the competition at the same level with the others [40]. The business should not just simply decide to put money into a business activity without prior background checking, if not, the money would not promise even a return in the future.

Therefore, this paper intent to identify global supply chain management challenges followed by its solutions. Some countermeasures should be developed in order to address the challenges that arise from the global supply chain management. The management perhaps cannot mitigate the problems or issues totally, but, at least some prevention taken in order to overcome them. A profound and aggressive initiative should be started internally, combining the company's strengths and resolving the weaknesses. Right after the internal information has been found, the external information which related to the environmental factors where covering the threats and opportunities also need to be studied properly. Hence, internal and external combinations will be the most powerful tool in mitigating the problem related to the supply chains. Later, the companies who operating extending the local business operation would not be disrupted anymore as they have done the analysis first before committing into the business operations.

Such an approach means that the paper is not a rigorous review of all issues connected with supply chain management but rather an overview of selected issues and a starting point for anyone who would like to get more familiar with this exciting field. The structure of the paper follows its purpose. Each of the selected issues is reviewed and illustrated with a short vignette.

\section{Literature Review}

\subsection{The Challenges in Supply Chain Management in India}

Since the paper focuses on what are the global supply chain challenges and solutions, hence we should begin on identifying the challenges and its solutions. The first scenario is from the country of India. The industry of India has been becoming the global manufacturing hub whereby its domestic and international markets have been widely portraying many opportunities to the world. Although, it would be much on bringing benefits to the country but generally there are some challenges on its supply chain. According to the research done by [1], there are many challenges faced in supply chain management in India. Initially comes from the suppliers. A lot of initiatives have been taken by the company to reduce the supplier's cost, responsiveness, reliability and its competitiveness. The supplier has brought many supply risks instituted towards handling company's order. The first of supply risks encountered by many business institutions in India is delaying in order receipt. The company or the business institution gets the materials ordered from the supplier which is considered too late. This issue is causing problem into company's production opera- 
tion. It cannot even proceed to the next business operation which is considered as the most important task to do which is the transformation process before offering the product to the end user. Second supply risk is mismatch in quantity supplied. Due to ineffective system that was used by the supplier, many firms suffered on the cost of returning back false ordered materials to the supplier or the waiting time has been spent on the way back to the supplier. This second risk whereby entailed in the very first challenge of firms should be monitored closely by the respective suppliers so that the firm in India would not bear too much cost in supply chain. Furthermore, the third supply risk in supplier point of view was known as inferior quality damaged. The supplier had indicated clearly that the quality in the discussion process where showing some standards and attainment had been put into the materials. But, when it comes to the reality, the suppliers were not giving the right quality or even did not achieve certain standard of procedure in the supplier point of view [5].

The customer's requirements which had become the factor in handling the downstream process also one of the challenges in Indian industry [18]. Each firm believed that the customer is the king of all, has the highest power rather than the firms who had offered products, and has the right whether to accept or reject the offers from the firms. This is tremendously showing that the customers always the priority of the firms before creating the products or services to them. The prominent problem is that the firms in India simply producing the products and services without doing some market research towards customers' preferences. They failed to produce the product that fulfilling the customer's needs and wants. This challenge is the crucial thing that the firms need to take into account when dealing with supply chain. It's not merely simply releasing the new products and services without considering what's going around the market. Supply chain management should meet optimally the customer's requirements in order to work efficiently and achieving firm's goals [28]. The firms who have failed to do customer's screening will incur high possible cost as it is producing products and services which do not meeting the customer's requirements. Sometimes, firms have done the customer's analysis but still failed to satisfy the customer needs and wants. Probably this is due to customer day by day is becoming too complex to anticipate on its preferences. Therefore, the customer's requirement has become one of the supply chain management challenges. This issue requires the firms to study the possible outcome thoroughly. If not then they may lose the customer in the future which categorized as the most important shareholders of the firm, where they opt to invest certain amount of money into the firms generally.

Furthermore, challenge that faced by the Indian's firms is the competition among the rivalry. Many new and existing firms in the market are competing each other's in delivering the best products and services to the customers. Perhaps, those who have a very high initial capital might do more as compared to those who have less capacity and capability. The competition style is more to who put more efforts will be always becoming the champion and winner for the competition. The gigantic player will always dominate the market whereby spending much effort on the supply chain management such as marketing, logistics and transportation, materials and distribution management. A study by [19], has shown has shown that the less capable may be left behind and drowned useless. The things are these firms had spent money on some supply chains and at the end getting nothing. Some issues also may arise from the tight competition, for instance a company wanted to seek out for low transportation cost. Due to prior dealt with big company; the transportation dealer might not consider reducing its price to the company who needs lower transportation cost. Thus, by hook or by crook, the company should take and bear the high cost instead. This could be the challenge that faced by the firms in India nowadays.

The next challenge in supply chain management faced by the Indian Industry is that when it has become as domestic and global market, the geographic distance indicated some issue to the firms which existed in India market. The terminology "scarcity" always present in the country. This term refers to a capacity that its lack, be deficient in, be short of, or require the most in the supply chain management. Many countries due to initiative in resolving the problem of scarcity have been seeking out many alternatives where taking in or bringing in some resources from the other countries [11]. This challenge can portray some risks on the rules and regulation, political issue, distance it takes, and cost of transporting the resources into the country. The geographical distance reflected that the flow of raw material from its origin to a destination will create some cost that may limit the firm's ability to due to the separation between two places at the time. The long distance subjects to high cost whereas short distance bears lower operating cost. Another issue may arise from the geographic distance is the possible load units and the conditions in which they can be carried. Volume of load units is influencing the ability to move raw materials from one place to another place. This flow has to be negotiated between providers and the firms that require the raw materials from the provider which is subject to the transportation cost with the container to load the units. Initially, this could involve monetary exchange from the provider and the firms that using the service. Additionally, it is also implying the speed, the economies scale and technology used in dispersing the amount of information. Thus, geographic distance should be able to covers the issues which if not may lead the firms to lodge huge amounts of tangible and intangible efforts.

Other than that the challenge found in Indian industry is the integration of supply chain. This is commonly implying where the specific strategies have been combined with the whole corporate business strategy. Many efforts have been allocated in identifying the internal strategies with the business vision instead of putting an effort in mitigating some issues arising from the external environment. Generally, the integration should not be internally merely but need to be done accordingly with the external environment factors [38]. In India, normally the Chief Executive Officer (CEO) would only rather concerns on how supply chain cuts its cost rather than exerting effort on combining internal and external environmental factors. The failure of combining between these two factors may lead to wasting money, time and effort in the future. Addressing both issues should be happened at a time to make sure that the firm can aim on one proportion.

The information sharing was also found as a challenge in Indian industry. Almost all firms refused to share the information with the third party due to some reasons that they afraid one party can take advantage to. The abusing on the information was frequently happen as it believes that the other parties could use the information in leveraging its efficiency and capabilities over others [45]. This assumption being assimilated throughout many firms profoundly. Although two parties are the partners in the same industry and business, the cost data such as the price of production and raw materials had hidden from the firm's knowledge. Due to monopolistic issue where one firm expecting the very best over the others, this company could exaggerate the information although the party has asked for that real information. Hence, the main issue here is in developing trust and cooperation among the partners is really difficult and complicated.

\subsection{The Supply Chain Management Challenges in To- day's Global Competitive Environment}

Nowadays, the competition among the business institutions in supply chain global competitive environment requires organizations not only to compete in their ability to enter new markets and achieve economies of scale but also in their ability to effectively administrate knowledge flows in an information-based economy [37]. Additionally, in order to increase competitiveness, challenges are faced in pursuing global efficiency, local responsiveness and at the same time effective knowledge and information transfer between subsidiaries. Business institutions not merely exerting efforts in lowering the cost but should be able to applying some 
knowledge in penetrating the market. Although, the knowledge may be varying but it is the most essential tool in tackling the prospects in the market. Similarly, many different strategies can be used to improving the competitiveness.

According to the research done by [13], initially managers faced some rigid decision in allocating resources into many activities. The tasks done must be addressing whether or not the firm able to save the cost or increase the profit. This decision is not aligned with other factors which might be considered as important as possible. Managers might opt to use the short cut but due to the inflexible decision in a daily basis, they cannot run away from its normal job responsibilities. The rigidness may restrict the managers to become more innovative with the new solutions in supply chain management. Managers would rather want to utilize the optimal ways in mitigating the problems, but constrained with this issue may lead to improper results or outcomes. As consequences, the company may be left behind among other competitors, unbearable solutions, and lots of costs incurred.

The researchers have also found that the regional representation on the global integrated process tend to create the challenges in the supply chain management [25]. As results from the global integrated process, the cost may increase tremendously, information infrastructure and the travel it takes from one place to another place. The firm needs to train a well capable representative to represents the company to other country with the home country language and culture as well. The starting process might incur high cost in developing the staff's skills and expertise. Additionally, the company also needs to shape the staffs which require long periods of times. So generally this is one of the challenges of supply chain management in global point view.

Lastly, in global supply chain management, it is facing a challenge known as procurement management. This is a typical manufacturing company needs to procure thousands of products from the many different suppliers. A study by [30] found the issues of complexity in procurement process which involving many complicated document to fill in, the empowerment where the manager in the company delegate the tasks by cooperating with the first line manager or the middle line of managers and fully integrated to the stakeholder and finance organization. If the staffs get familiarize with the documents that involved in the business process would not be a problem. But what if the staff is the first time experience the job and never comfortable with the tasks. Mistakes may be leading to huge losses that probably in the future will be more chaotic.

\subsection{Current Issues and Challenges of Supply Chain Management}

In [20] highlighted the challenges to successfully implement supply chain management nowadays in competitive environment of business by firms. The success of supply chain management practice only can be achieved if issue surrounding it understood by firms precisely or else it will lead to failure in implementing it. They also stated that material and information flow is important in supply chain management as both interdependent with each other. There are 6 issues and challenges discussed in this paper by researchers.

Firstly, strategic insights which focuses on bullwhip effect that happen when the chain is short of information and coordination. This will give impact as the rise of fluctuation in demand happen that move up along in supply chain, as serious fluctuation level can happen that start from small scale if no measures taken to prevent the fluctuation [42].

Secondly, business redesign in supply chain management. This centres on how to choose the best way to improve supply chain management through different set of methods of business redesign [41]. Specialist centre around two strategies which Business Process Reengineering (BPR) which business approaches, practices and methods is inspected fundamentally, revaluates them and after that upgrades the mission-basic items, procedures and administra- tions. BPR looks for changes by hoisting proficiency and viability of the business procedure that exist inside and crosswise over associations. Next, Continuous Process Improvement (CPI). CPI focus more on the small scale which more specific change made in the business model. It also focuses on the relationship with customers as what customer need, what can be offered to them, and what comes about if there is any nonappearance of need fulfilment with them by making society of industrious change in the zones of trustworthiness, process lengths, costs in regards to less total resource use, quality, and effectiveness. Six Sigma and Total Quality Management (TQM) are instances of approaches to manage CPI.

Thirdly, supply chain risks which leads to the administration of supply chain problems. In [23] added on the formation of supply chain chance administration with a specific end goal to do examination on the conceivable problems in supply chain and develop the possible ways to manage it. The researcher stated that dealing with many different suppliers that operates in various different environment and market would be the risk to supply chain as many different kind of risks will be resulted from this dealings of different kind of suppliers in different environments. Researchers later proposed the approach that can distinguish between different kind of risks that can encourages the organization to settle on a more educated choice with reference to the amount risk it will go out on a limb will it alleviate.

Fourthly, supply chain frameworks and standards goes hand in hand with the challenge in choosing the best business frameworks and standards from various sources. The issue rise as to which standard is immaculate with supply chain management. Experts proposed Supply-Chain Operations Reference (SCOR) that can help relationship in growing the feasibility of their supply chains, and to give a method based approach to manage supply chain management [34]. The SCOR exhibit gives a run of the mill method arranged lingo for granting among supply-chain connections.

Besides, performance measurement in supply chain management. This emphasis on the change of supply chain with a specific end goal to increase upper hand through the conceivable great performance measurement approach. Looks into expressed that that performance estimation should centre around two associated yet at the same time distinguishable territories, in which estimation of performance of every provider and the estimation of supply chain all in all is two diverse separate things in performance measurement. Researchers suggested different approaches such as key performance indicators (KPIs), balanced scorecards and the use of simulations in application of supply chain management performance measurement [4].

Lastly, Information System (IS) support for supply chain management which stresses on the headway of innovation and data framework in the supply chain management. According to [32], IS is all about how firms can adopt this advancement with supply chain to gain competitive advantage. Real issues to make it accomplishment in IS bolster are institutionalization, framework ebusiness, production network segments and incorporation as proposed. Researchers expressed that the genuine problems of implementation are crossing over any barrier between information technology, process and performance consequently suggested the use of supply chain management software.

\subsection{Challenges in Supply Chain Management in Up- stream Sector of Oil and Gas Industry}

According to [1], supply chain management is characterized as administration of substances straightforwardly engaged with the upstream and downstream stream of items, administrations, funds, or potentially data from a source to a client. Inventory network methods are the fundamental spine to business affiliations today. Supply chain management incorporates enhancing undertakings to extend both speed and profitability. The upstream division of oil and gas industry is locked in with an overall supply-chain that 
consolidates family unit and worldwide transportation, asking for and stock detectable quality and control, materials dealing with, import/exchange help and information development. The eccentric thought of the oilfield supply chain and the contemporary business conditions contains a lot of defencelessness and multifaceted nature to the extent what strategies and change of practices should be considered in controlling and managing such worldwide supply chains. There are 8 challenges of supply chain management proposed by researchers.

Firstly, remote geographic location [24]. This focus on the limit of availability of oil location in easy area made oil industry to find oil in more remote area location. This become a problem due to lack of logistic capabilities and the effort to get a permit and to difficulty to build infrastructures that can make ease for oil companies. Then, inventory management. As the difficulty from previous transportation problems for delivery from suppliers, Oil companies tend to keep the surplus of inventory. This to avoid out of stocks problem due to delivery difficulty. This next will create high inventory cost to companies.

Thirdly, transportation. Challenge in to keep in touch with supply chain partners due to remote location. This create the high cost for transportation and also greatly time delay that can make it worst as operation can be shut down. Next, the project supply chain challenges. This focus on the difficulty to build infrastructures due to huge investments needed. Remote location will need a longer and safer quality of infrastructures of road, pipelines, and building rigs [8].

In [8] further added on challenge that involve supply chain inbound and outbound. For inbound, amid the tasks arrange, different materials like bore packaging, boring tools, boring channels, water, boring mud, ointments and so forth are required to be brought and put away which in remote areas is a troublesome suggestion. For shale gas task, water, sand and fracking chemicals in immense amounts are required to be conveyed to the site. For outbound, the difficulties in taking consideration the last delivered gas and oil so it can securely touch base to customers.

Final two challenges are the remote workers supply chain challenges as the challenges to take care workers in remote location that need higher need of support by oil companies' operators and the emergency supply chain challenge which the focus on the challenges during emergency happen in stream like fire, leaks and etc. It will more difficult to have emergency plans and rescue in remote locations to protect their workers and inventories during emergency happen [23].

In conclusion, the objective of supply chain management is to give most extreme client benefits at the least conceivable cost. It obviously difficult for oil and gas companies especially in remote location to maintain low cost but with proper and effective supply chain efficiencies plans, these challenges can be overcome by oil companies.

\subsection{The Challenges in Supply Chain from the Impact of Fourth Industrial Revolution}

The fourth industrial revolution is a combination of technologies breakthrough such as artificial intelligence, internet of things, advanced robotics, virtual and augmented reality, wearable and additive manufacturing [26]. Transformation production process and business models of the future is for sure with this technology breakthrough. In conjunction with this the business leaders can no longer focus on advancement on their own sectors but need to widen the scope to recognize potential revolutions and troubles in entire chain of suppliers, customers and end-to-end markets which supply chain made of.

According to [3], all steps in production and business models in majority segments of economy being transformed by disruptive technologies. At an extraordinary degree and pace the consumers demand for product, manufacturing processes and the global supply chains management are being reformed. Leaders in the industry trust that the innovative technological resolutions emerging such as artificial intelligence, internet of things, advanced robotics, virtual and augmented reality and additive manufacturing are changing traditional ways of creating value. Eventually, these transformations are making costs of deploying technology on the down trend and the influence of international differences in cost of labour significant production location selection as it was in the pass. These trends will change trajectory of goods and be a challenge for the supply chain. Regional and local flows more significant to intercontinental trade.

Fourth industrial revolution brings the technology which not only changing the method of production and managing supply chain, not only that but the way formation of new value chains. Partnership between companies at numerous stage of the value chain is taking totally a new form with the digital connectivity [39]. Below are examples of developments that are expected to be key this process:

i. Open innovation, is transparency of companies in concerning other customers and companies in development and innovation processes or products [44]. Internet has evolved largely the way the world communicates and innovates. Open innovation stages helping companies, independent of their magnitude or geographical reach, to better innovate by crowd sourcing designs, thoughts, and other solutions.

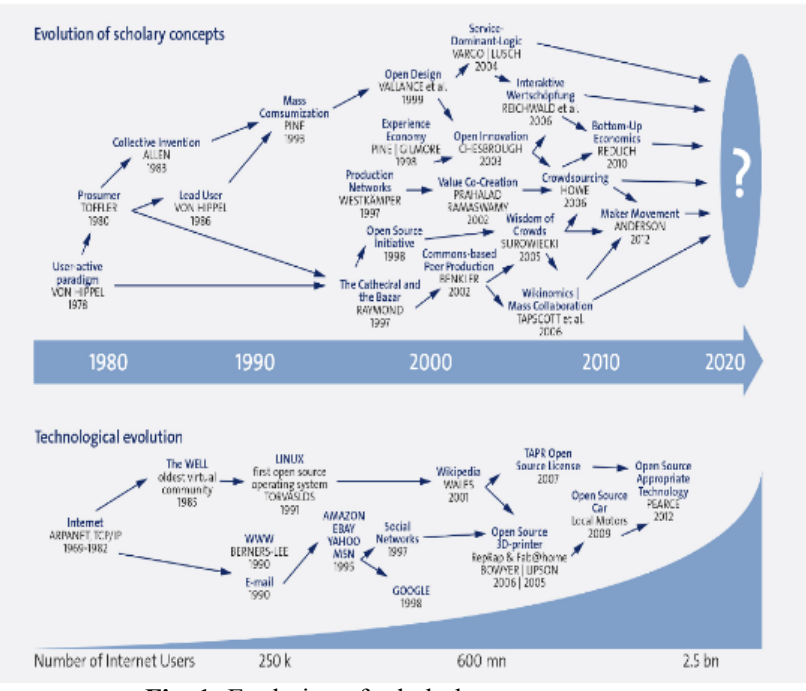

Fig. 1: Evolution of scholarly concepts

ii. A study by [21] explained distributed manufacturing as method of broad decentralization of production structures and eliminating typical manufacturing models. Beginning of innovative manufacturing technologies has made the spread manufacturing became possible in the current era. Distributed manufacturing idea was created in theoretical and practical merger of foundation of cutting-edge Fourth Industrial Revolution technologies such as internet of things (IoT), additive manufacturing and cloud computing. Fundamental is to place production nearer to the customer and to involve customer more efficiently in local production processes. The cost and lead time be reduced significantly. As an example the production can be driven by a regionalized network of 3D printers through cloud computing interconnecting producers' systems. 


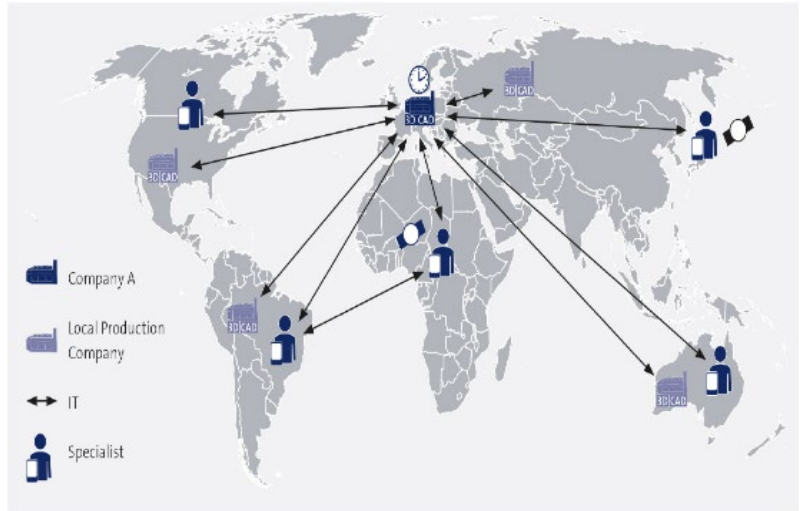

Fig. 2: Concept of distributed manufacturing for wristwatches

iii. New partnership models between companies, mainly horizontally, but also vertically [6]. Supply chain is basically a partnership ecosystem. As time moves on many forms of partnership between associates along the supply chain have developed. Momentums created through digitalization which gives to this reality new complexity. As a result, less important become the company boundaries to improve the efficiency and flexibility of supply chains. Vertical collaboration models common across industries but from the competitive standpoint horizontal partnership is always identified as a risk. But now high potential of cost savings through joint procurement services and shared use of transport and storage capacities is the key motivation for horizontal collaboration. Risks along the chain is mitigating as sharing of information to seen as an enabler of horizontal partnership.

Here come the challenges that are faced in supply chain due this to this Fourth Industrial Revolution. The first challenge identified as the execution of open innovation in conjunction with horizontal collaboration concepts [2]. This will be the key to define competitiveness in the Fourth Industrial Revolution end to end in the supply chain, the roles of stakeholders are likely to change. Companies need to be ready for this development and this will surely be a challenge.

The next challenge will be supply chain performance itself as highlighted in the study of [35]. Almost $75 \%$ companies will scuffle to understand their end-to-end supply chain visibility through the year of 2018. Less understanding in the end-to-end supply chain information slows innovation. Technologies and data collection out of the Fourth Industrial revolution are not being gained to the maximum extent possible. Supply chain executives have limited or to the worst case totally no information on their supply chains. A new level of supply chain distinguish ability is crucial to transform supply chain. IoT and artificial intelligence will be the base for the necessary transformation.

The following challenge in supply chain is the organizational agility. The old method supply chain is optimized to the maximum Products, suppliers and customers increased significantly. Supply chain integration is reaching its limits. Additional layers are making it more complex and constraining the originally laid-out infrastructure. To top it new customers with new hopes, rise. Hence new kind structural and organizational alertness need to be achieved and technology from fourth industrial revolution will allow the shift [46].

Shortage of talent and the right-skilling also will be challenges in the supply chain [14]. New technologies surely require new competencies and skills at all levels. To cater for this a multistakeholder ecosystem for skilling surely needed.

The final challenge by [36] is backing for SMEs. Big companies are able to invest in research and development but small and medium-sized enterprises (SME) basically the main providers to growth and job creation. Here the governments must to make sure SMEs can also advance the aids of fourth industrial revolution technologies. Venture in technologies as distributed manufacturing will also support growing nations recognize and speed up their industrialization process.

\subsection{Analysis of Supply Chain Management in HaiHa Confectionery Joint-Stock Company (HAIHACO) and Developing Plan for its System}

In [33] conducted a case study in HaiHa and the role of HaiHa's supplier is clear. Teamwork among HaiHa's suppliers, Haiha and the distributors is the chain. With vast capital of $50 \%$ share go to the government of Vietnam. Just-in-time production system of HaiHa's is working great. This is strong benefit that HaiHa must keep take advantage of. They can earn more profit can by putting away more at the low price point and delay the procurement. But disadvantage in their supply chain management plan is the connection with their distributors which cause for losing their market share. HaiHa built own store chain and most of them are near the factory. Anyhow the cooperation system with hypermarkets, shops and supermarkets not so good. The major issue for HaiHa's the situation with distributors. Distributor always deficiencies in capital, so they prefer to sell manufacturer's product under consignment conditions. Understanding this HaiHa's competitors start to put on consignment contract with all supermarkets. These results HaiHa's products keep disappearing in the market.

Managing pricing and quality in supply chain is also another challenge in supply chain [15]. Cheap price wish of every company and driving factor for major decision. But to be mined also the lowest price does not mean the best quality. All product and service, the price influences the decision, but selecting only by the price will turn out to be a catastrophe. As the manager, choosing the best bid is not always the cheapest one but the most appropriate. The manager needs to work smartly on the strategic supply management tools and processes in order to select the best value that one bid can bring to the organization.

Task management is another challenge in supply chain. As an example in the case of HaiHa, they have to find out what commodity group has to do with their synchronized supply chain management. In fact, it is it is everything. As for HaiHa now, they have few factories and departments in many cities North Vietnam anyway no proper connection among all their divisions. In the trading department only comprises people, specialize in many things. One person has to do both domestic and international trade, another person can do inventory and also delivery control. These personals have to be in charge of many things but actually specializing in nothing. This is a mess in organizing, having database, this will have struggle in their input and output information. This is because one person is responsible for many tasks and one task is many people's accountability [15].

\subsection{Supply Chain Design: Issues, Challenges, Frame- works and Solution}

In this turbulent world, efficient supply chain is important and much needed for survival of business. With this current economic situation, it plays a crucial and important role in ensuring efficient management of the flow of goods and services. Challenges in related areas of the supply chain management are written out in this conceptual paper reviews issues. Frequent matters are highlighted and recognized as vital in supply chain management or its design. A collective of research discoveries and practical suggestions are gathered together to make overview on the background research.

According to [29], supply chain management should be effective if it's planned and purposive. In this research, the firm supply chain result is defined by a value-driven supply chain that's combined with the strategic significances. The firm deliberate management action and strategic company investments aimed to acquire, develop and configure the suitable resources, methods and 
metrics. In understanding supply chain plan, three key level components are proposed including influencers, plan choices and building pieces. Influencers are higher-level studies such as the trade and political environment, the commerce demonstrate utilized, the firm's required outcomes and the supply chain life cycle. Social, behavioural and physical/structural plan components that characterize a supply chain is integrate with the design result. Building blocks incorporate stock, transportation, innovation choices and capacity that are utilized to actualize the supply chain. Three levels of examination should be implementing in supply chain plan. This article in this unusual matter is presented within the setting of these levels of investigation and it is recommended that it can be sought after in light of this system which highlights ranges that are covered in this uncommon issue and ranges where we can inquire on existing opportunities.

A tool that available to managers is one of the most perilous tools available. That is supply chain design (and redesign) [17]. However, the basic component, whereas as often as possible utilized, is ineffectively caught on. Subsequently, this uncommon issue early on article started by suggesting a three-level system. Not for just for understanding the development but to further understand in the co current and examination on the subject of supply chain design. The three variables of forbid components incorporate influencers, building pieces and plan choices are significant to the key victory of supply chain [10]. Eight articles had been summarized and included in the system. This works in different countries such as Asia, Europe and North America over various business included in expository, observational and hypothetical papers.

Whereas, this unusual issue grants works of inquire about that trace on various distinctive measurements of the projected system. Various zones stay unharmed by both unusual issue and inquire about in common. As such, we have highlighted various openings for future inquire about that can construct upon that which has as of now been distributed. Furthermore, other zones of potential future investigate germane to supply chain plan have been displayed, counting: multi-industry ponders, supply chain move considers, the effect of varying craved results, and the effect of the supply chain life cycle.

Comprehended or summed up by any single measurement, supply chain plan could be a wealthy concept, not one or the other is it sensible to anticipate any single consider completely to test and investigate all important components at the same time [22]. Future taught about it will may in fact emphasis on as it were one (or a couple) of striking measurement(s) examined.

In any case, these studies will be well served by setting centre of investigate inside this suggested framework so that fitting control factors and other possibly perplexing components can be taken under consideration. As such, information and understanding on this wealthy point can continue with a common base of presumptions, definitions and systems that will direct the definition of curiously and important investigate questions. The outcomes of such endeavours will empower the inquire about community not as it were to distinguish stand-alone variables of effective supply chain plan, but too to empower the gathering of a complex astound whose different pieces work together to organize an in general supply.

\subsection{Supply Chain Management Integration (SCMI): Critical Problems and Solutions}

Supply chain plan may be a wealthy idea that cannot be understood or summed up by any measurement, not one or the other is it sensible towards anticipate any solo ponder completely to test and investigate all pertinent aspects instantaneously. When arranging the supply chain management, association must take important note to adjust company's SCMI techniques. Not only that, the conceivable request and supply vulnerabilities and other components that can cause commerce dangers. To dodge the SCMI domino impact on the organization's execution, basic issues and arrangements ought to be dealt with careful. Thus, a study by [31] proposed on supply chain management analytics system that caters to commerce dangers and the supply chain management domino impact powerfully as appeared.

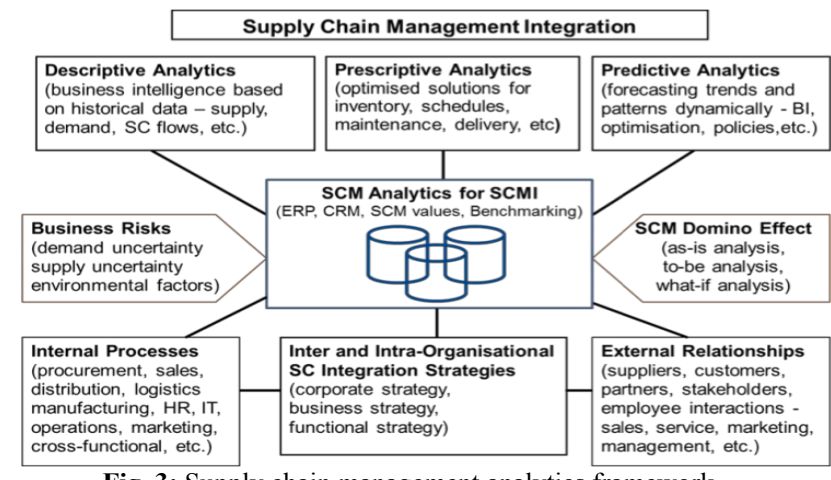

Fig. 3: Supply chain management analytics framework

Decision-makers ought to consider costs, benefits, and dangers within the advertised environment some time recently adjusting the SCMI procedure. Innovation alone cannot make a fruitful SCMI. There's a got to look at the enormous picture, particularly troublesome behavioural designs and dangers in executing the SCMI. Prescient analytics are conceivable. Moderate of the development of supply chain management is the result from coordinate failure of SC members' procedures. In this manner, supply chain management ought to bargain with the administration of the whole supply chain. Thus, to embrace the coordination in daily operations of the supply chain and SCMI as an entirety, expressive and prescriptive analytics ought to be important [16].

In spite of the fact that supply chain management can give numerous benefits to the association by [27], it requires sensible venture and commitment. In this way, it is imperative to conduct a cost/benefit examination, sometime recently receiving the SCMI procedure. To adjust supply chain procedure, align with the corporate technique requirement for companies must be fulfil.

By considerations the current state of SCMI in different industry divisions, as well as its down to earth usage the exploratory consider was conducted utilizing online Web discourse gathering and will be valuable to the supply chain administration specialists and analysts fascinated [9]. Supply chain integration will be valuable to the directors to move forward the SCMI execution in an association, and analysts will be able to utilize the system to conduct assist in-depth thinks about on SCMI by having the analytics system for the limitation of the considered may be a little test utilized to recognize SCMI issues and recommended arrangements. The come about cannot be summed up.

\section{Methodology}

The methodology to address the global supply chain management on the challenges and its solutions was to engage in a field research through the qualitative methods where reviewing few case studies has been brought into our discussion. This method was chosen to get a deeper insight into the issues from different perspectives of researchers.

The main research questions that were figured out from the case studies are indicated below;

1. What is global supply chain?

2. What are the global supply chain management challenges?

3. What are the solutions for the global supply chain management challenges?

A literature survey was employed as the research methodology in the study to identify solutions for challenges appear in supply chain management globally. The literature on global supply chain management was collected primary from journals in the areas of operations management, supply chain, operations research, and information systems. Dissertations, textbooks, unpublished work- 
ing papers, and conference papers were excluded for the sake of rigorousness. The literature search included journals published by numerous publishers, in particular Elsevier, Emerald, and Taylor and Francis, together with journals such as Management Science and Operations Research. The primary aim of the literature search was to help researchers and practitioners develop an effective supply chain management. The literature on global supply chain management and some associated references were classified according to this objective and are reviewed accordingly.

\section{Conclusion}

The paper has tackled a vital challenge to provide a comprehensive review of several interconnected challenges in supply chain management worldwide. Only continuous efforts in each of the mentioned areas assure efficiency and success. As a conclusion, by putting attention on the global supply chain management challenges and its solutions, it can play the most important roles for the businesses to participate successfully in the international business. It explored the reality of obstacles that prevails in manufacturing in Indian, HaiHa, and other global perspectives. But, through the solutions, by hooked or by crooked, companies may get the profit and are able to resolve the problem.

Therefore, as a future work, the organizations who wish to participate in global level must be aware and careful on the existence of several challenges. A tight and close investigation must be done thoroughly in order to achieve their goals and targets. These efforts might enable managers terminate the obstacles hinder supply chain management practicing through providing sophisticated information system for information sharing among supply chain members, enhancing the cooperation among supply chain members, motivating suppliers and customers to have participate in the supply chain and adapting new techniques in managing inventories throughout the entire supply chain.

We hope that our paper is a small but significant contribution in this quest. Obviously the paper has some limitations. The choice of the included issues was mainly arbitrarily, based on authors' practical and theoretical knowledge. The presented cases are not a full rigorous cases but rather short vignettes; however, references to full cases were provided. Finally, as the only certainties in today's world are frequent changes it is likely that the challenges of supply chain management will also change or increase in the coming years. However, the main concepts outlined in this paper are likely to remain rather similar.

\section{Acknowledgement}

The corresponding author would like to thank Universiti Teknika Malaysia Melaka for the UTeM Zamalah Scheme for sponsorship.

\section{References}

[1] Agarwal, M., Sharma, R., \& Alex, L. M. (2016). Challenges in supply chain management in upstream sector of oil and gas industry. https://www.researchgate.net/publication/315743216 Challenges i n_Supply_Chain_Management_in_Upstream_Sector_of_Oil_and_ Gas Industry.

[2] Akinwale, Y. O. (2018). Empirical analysis of inbound open innovation and small and medium-sized enterprises' performance: Evidence from oil and gas industry. South African Journal of Economic and Management Sciences, 21(1), 1-9.

[3] Amshoff, B., Dülme, C., Echterfeld, J., \& Gausemeier, J. (2015). Business model patterns for disruptive technologies. International Journal of Innovation Management, 19(3), 1-22.

[4] Anand, N., \& Grover, N. (2015). Measuring retail supply chain performance: Theoretical model using key performance indicators (KPIs). Benchmarking: An International Journal, 22(1), 135-166.

[5] Awate, S., Larsen, M. M., \& Mudambi, R. (2015). Accessing vs sourcing knowledge: A comparative study of R\&D internationalization between emerging and advanced economy firms. Journal of International Business Studies, 46(1), 63-86.

[6] Badea, A., Prostean, G., Goncalves, G., \& Allaoui, H. (2014) Assessing risk factors in collaborative supply chain with the analytic hierarchy process (AHP). Procedia-Social and Behavioral Sciences, 124, 114-123.

[7] Bala, K. (2014). Supply chain management: Some issues and challenges-A review. International Journal of Current Engineering and Technology, 4(2), 947-953.

[8] Banker, S. (2014). The upstream shale oil supply chain. https://www.forbes.com/sites/stevebanker/2014/08/08/theupstream-unconventional-oil-gas-supply-chain/\#49b8f7aa74a0.

[9] Bohne, A. (2017). Decision-making and the internet of things: Influences and impacts on business decisions and supply chains. Bachelor thesis, South-Eastern Finland University of Applied Sciences.

[10] Chandler, M. T. (2016). How performance management is killing performance-And what to do about it: Rethink, redesign, reboot. Berrett-Koehler Publishers.

[11] Christopher, M. (2016). Logistics and supply chain management. Pearson.

[12] Crane, A., \& Matten, D. (2016). Business ethics: Managing corporate citizenship and sustainability in the age of globalization. Oxford University Press.

[13] Deveshwar, A., \& Rathee, R. (2010). Challenges for supply chain management in today's global competitive environment. International Review of Business Research Papers, 6(2), 194-203.

[14] Dubey, R., \& Gunasekaran, A. (2015). Shortage of sustainable supply chain talent: An industrial training framework. Industrial and Commercial Training, 47(2), 86-94.

[15] Fernie, J., \& Sparks, L. (2014). Logistics and retail management: Emerging issues and new challenges in the retail supply chain. Kogan Page Publishers.

[16] Fredendall, L. D., \& Hill, E. (2016). Basics of supply chain management. CRC Press.

[17] Gattorna, J. (2015). Dynamic supply chains. Pearson Education Limited.

[18] Govindan, K., Kaliyan, M., Kannan, D., \& Haq, A. N. (2014) Barriers analysis for green supply chain management implementation in Indian industries using analytic hierarchy process. International Journal of Production Economics, 147, 555568.

[19] Grant, D. B., Wong, C. Y., \& Trautrims, A. (2017). Sustainable logistics and supply chain management: Principles and practices for sustainable operations and management. Kogan Page Publishers.

[20] Groznika, A., \& Trkman, P. (2012). Current issues and challenges of supply chain management. Economic Research-Ekonomska Istraživanja, 25(4), 1101-1112.

[21] Gwamuri, J., Wittbrodt, B. T., Anzalone, N. C., \& Pearce, J. M. (2014). Reversing the trend of large scale and centralization in manufacturing: The case of distributed manufacturing of customizable 3-D-printable self-adjustable glasses. Challenges in Sustainability, 2(1), 30-40.

[22] Mustafa, S. K., Musa, H., Abdullah, A. R., \& Azmi, F. R. (2017). The influences of consumer preference characteristics towards green product: A case of naturemill bin. International Journal of Human and Technology Interaction, 1(1), 43-50.

[23] Heckmann, I., Comes, T., \& Nickel, S. (2015). A critical review on supply chain risk-Definition, measure and modeling. Omega, 52 , 119-132.

[24] Herrera, C. I. (2012). Outsourcing logistics in the oil and gas industry. Senior scholars thesis, Texas A\&M University.

[25] Hugos, M. H. (2018). Essentials of supply chain management. John Wiley and Sons.

[26] Lasi, H., Fettke, P., Kemper, H. G., Feld, T., \& Hoffmann, M. (2014). Industry 4.0. Business and Information Systems Engineering, 6(4), 239-242.

[27] Azmi, F.R., Abdullah, A., Bakri, M.H., \& Musa, H (2018). Perception of small medium and enterprises towards Halal food supply chain in Malaysia. International Journal of Mechanical Engineering and Technology, 9(11), 821-828.

[28] Azmi, F., Abdullah, A., Bakri, M., Musa, H., \& Jayakrishnan, M. (2018). The adoption of halal food supply chain towards the performance of food manufacturing in Malaysia. Management Science Letters, 8(7), 755-766.

[29] Melnyk, S. A., Narasimhan, R., \& DeCampos, H. A. (2014). Supply chain design: Issues, challenges, frameworks and solutions. International Journal of Production Research, 52(7), 1-10. 
[30] Monczka, R. M., Handfield, R. B., Giunipero, L. C., \& Patterson, J. L. (2015). Purchasing and supply chain management. Cengage Learning.

[31] Msimangira, K. A., \& Venkatraman, S. (2014). Supply chain management integration: Critical problems and solutions. Operations and Supply Chain Management, 7(1), 23-31.

[32] Musa, H. M. (2014). Analyzing factors towards adopting ICT within supply network in the UK. Journal of Technology Management and Technopreneurship, 2(1), 19-35.

[33] Nguyen, H. (2016). Analysis of supply chain management (SCM) in HaiHa confectionery joint-stock company (HAIHACO) and developing plan for its system. Banchelor thesis, Satakunta University of Applied Sciences.

[34] Ntabe, E. N., LeBel, L., Munson, A. D., \& Santa-Eulalia, L. A. (2015). A systematic literature review of the supply chain operations reference (SCOR) model application with special attention to environmental issues. International Journal of Production Economics, 169, 310-332.

[35] Oksala, M. (2018). Key factors in SME supply chain risk assessment. Master thesis, Lappeenranta University of Technology.

[36] Palomero, S., \& Chalmeta, R. (2014). A guide for supply chain integration in SMEs. Production Planning and Control, 25(5), 372400.

[37] Patil, M. (2015). Challenges for supply chain management in today's global competitive environment. European Journal of Business and Management, 7(10), 61-63.

[38] Ralston, P. M., Blackhurst, J., Cantor, D. E., \& Crum, M. R. (2015). A structure-conduct-performance perspective of how strategic supply chain integration affects firm performance. Journal of Supply Chain Management, 51(2), 47-64.

[39] Ross, D. F. (2016). Introduction to e-supply chain management: Engaging technology to build market-winning business partnerships. CRC Press.

[40] Rushton, A., Croucher, P., \& Baker, P. (2014). The handbook of logistics and distribution management: Understanding the supply chain. Kogan Page Publishers.

[41] Schaltegger, S., \& Burritt, R. (2014). Measuring and managing sustainability performance of supply chains: Review and sustainability supply chain management framework. Supply Chain Management, 19(3), 232-241.

[42] Wang, X., \& Disney, S. M. (2016). The bullwhip effect: Progress, trends and directions. European Journal of Operational Research, 250(3), 691-701.

[43] Waters, D., \& Rinsler, S. (2014). Global logistics: New directions in supply chain management. Kogan Page Publishers.

[44] Rajah, N., \& Aris, A. (2018). The role of human resource development in the relationship between intrapreneurial competencies and innovative work behavior: A case study. Journal of National Academy of Managerial Staff of Culture and Arts Herald, 4, 441-448.

[45] Wu, L., Chuang, C. H., \& Hsu, C. H. (2014). Information sharing and collaborative behaviors in enabling supply chain performance: A social exchange perspective. International Journal of Production Economics, 148, 122-132.

[46] Yusuf, Y. Y., Gunasekaran, A., Musa, A., Dauda, M., El-Berishy, N. M., \& Cang, S. (2014). A relational study of supply chain agility, competitiveness and business performance in the oil and gas industry. International Journal of Production Economics, 147, 531543 